\title{
PRECONCEPTION CARE UTILIZATION AMONG CHILDBEARING WOMEN IN SOUTH-EAST NIGERIA
}

\author{
Chika C.H. Odira, Edith N. Chiejina, Christiana N. Okafor \\ and Adaobi Maryann Ibekwe
}

${ }^{1}$ Department of Nursing Science, Faculty of Health Sciences and Technology, Nnamdi Azikiwe University Awka, Anambra State, Nigeria. Email: chikachioma@gmail.com

${ }^{2}$ Department of Nursing Science, Faculty of Health Sciences and Technology, Nnamdi Azikiwe University Awka, Anambra State, Nigeria. Email: nkechichiejina@yahoo.com

${ }^{3}$ Department of Nursing Science, Faculty of Health Sciences and Technology, Nnamdi Azikiwe University Awka, Anambra State, Nigeria. Email: christyokafor30@gmail.com

${ }^{4}$ Department of Nursing Science, Faculty of Health Sciences and Technology, Nnamdi Azikiwe University Awka, Anambra State, Nigeria. Email: adaobiibekwe2020@ gmail.com

Cite this article:

Chika C.H.O., Edith N.C., Christiana N.O., Adaobi M.I. (2021), Preconception Care Utilization among

Childbearing Women in South-East Nigeria. African Journal of Health, Nursing and Midwifery 4(6), 1-13. DOI: 10.52589/AJHNM5MRKM80J.

\section{Manuscript History}

Received: 13 Aug 2021

Accepted: 8 Sept 2021

Published: 22 Sept 2021

Copyright $\odot 2020$ The Author(s). This is an Open Access article distributed under the terms of Creative Commons AttributionNonCommercial-NoDerivatives 4.0 International (CC BY-NC-ND 4.0 ), which permits anyone to share, use, reproduce and redistribute in any medium, provided the original author and source are credited.
ABSTRACT: Adverse pregnancy outcomes remain a challenging health problem in Nigeria. Before conception, couples need to utilize preconception care which is meant to address most of the reproductive health risks. However, the use of this service and its determinants is not well investigated globally. This Cross-sectional study was aimed at assessing the utilization of preconception care and its determinants among mothers in South-East Nigeria. Pre-tested and validated structured Questionnaire on Preconception Care Utilization was used to collect data from 350 postnatal women who were systematically selected from 33 sampled health facilities. Data were collated and entered into SPSS version 20. Binary logistic regression was used to determine the association between the demographic characteristics of the mothers and the utilization of preconception care. Statistical significance was set at $p<0.05$. Results show that only $23.4 \%$ of the mothers utilized preconception care. Parity, employment status, and pregnancy intention were significantly associated with preconception care utilization. The odd of utilizing preconception care were $60.2 \%$ lower among multiparous women than primiparous women. Workingclass mothers were more than $70 \%$ less likely to utilize preconception care than mothers who were not employed. Mothers whose pregnancy was intended were 3.4 times more likely to utilized preconception care than mothers whose pregnancy was unintended. Health facilities should establish functional clinics with the availability of evidence-based guidelines to improve uptake of preconception care. Health care professionals should intensify their efforts in encouraging women to receive preconception care.

KEYWORDS: Preconception care, Utilization, Childbearing women, Reproductive Health Clinic, Socio-demographic-obstetric determinants, South-East Nigeria 


\section{INTRODUCTION}

At all levels of healthcare provision, whether in the community, primary healthcare centres and referral settings, preconception care should be provided. Preconception care is defined as the promotion of the health and well-being of a woman and her partner before pregnancy (Zhao et al, 2014). The care given to childbearing women to ensure they are in good health before they become pregnant is an essential component to optimize the health and development of future offspring (Asresu, Hailu, Girmay, Abrha, and Weldearegay, 2019). Preconception care improves the health of women and men while reducing the problems that their children will experience: prematurity, low birth weight, birth defects or other birth-related conditions that could hinder optimal child development (Williams, Zapata, D'Angelo, Harrison and Morrow, 2012). According to Steel, Lucke, and Adams (2015), preconception care has received increased attention due to increasing evidence that maternal health before conception can directly affect the health of the mother and the foetal environment during pregnancy. Zhao et al (2014) stated that improving preconception health can result in improved reproductive health outcomes.

Preconception care is one of the important components of health care for every woman of reproductive age. The adoption of this care will assist the healthcare system to shift from the delivery of procedure-based acute care to the provision of counselling-based preventive care (Akinajo, Osanyin and Okojie, 2019). Components of preconception care include family planning, prevention and management of sexually transmitted infections including HIV, Folic acid fortification/supplementation to prevent neural tube defects, screening for and treatment of medical and infectious diseases, screening for unhealthy lifestyles and health teaching and genetic counselling (WHO, 2013a). There is growing evidence that preconception care may have an important role in preventing short and long term adverse health consequences for women and their offspring (Steel et al., 2015). According to WHO (2016), preconception care has a positive impact on reduction in mortality and decrease the risk of adverse health effects for the woman, foetus, and neonate by optimizing the woman's health and knowledge before planning and conceiving a pregnancy (Khan, 2018).

Globally, 4 out of every 10 women conceive without planning for the pregnancy (WHO, $2013 \mathrm{~b}$ ). It was therefore estimated that $40 \%$ of pregnancies miss the essential health interventions required before pregnancy (Olowokere, Komolafe and Owofadeju, 2015). To address this pitfall, the Centre for Disease Control (CDC) recommends risk assessment and counselling for all women of childbearing age as part of primary health care visits in order to improve pregnancy outcomes (Kassa and Yohannes, 2018). Consequently, preconception care has found a place in the continuum of care aimed at improving maternal, newborn and child health in low and middle-income countries (Mazza and Chapman, 2010).

Globally, evidence shows that preconception care utilization is generally low. Studies conducted in developing countries like Sudan, (Ahmed, Elbashir, Mohamed, Saeed and Alawad, 2015); Ethiopia (Demisse, Aliyu, Kitila, Tafesse, Kelem and Zerihun, 2019); Brazil (Borges, Santos, Nascimento, Chofakian, and Sponholz, 2016) and Sri Lanka (Patabendige, 2012) reported preconception care utilization of $9 \%, 13.4 \%, 15.9 \%$ and $27.2 \%$ respectively. Utilization of preconception care was slightly higher in developed countries like London, 27\% (Stephenson, Patel, Barrett, Howden, Copas, Ojukwu, and Shawe,2014); Saudi Arabia, 29.3\% (Madanat and Sheshah, 2014) and Maryland, 32\% (Maryland Pregnancy Risk Assessment Monitoring System, 2013). A study conducted in some states in Nigeria also revealed low 
preconception care utilization. A study in Abakaliki, Ebonyi State, South-East Nigeria revealed that only $10.3 \%$ received preconception care (Ekem, Lawani, Onoh, Iyoke, Ajah, Onwe ...Okafor, 2018). Another study conducted in Lagos University Teaching Hospital (LUTH), South-West Nigeria revealed that $34.2 \%$ of their study participants received preconception care before index pregnancy (Akinajo, Osanyin and Okojie, 2019) which showed utilization slightly higher than that of developed countries.

Age, marital status, education, parity and occupation were noted as significant determinants of PCC uptake by Okemo, Temmerman, Mwaniki, and Kamya (2020).

Despite the proven pieces of evidence that increase access to quality preconception and interconception care reduce the risk of maternal and infant mortality and pregnancy-related complications (Demisse, Aliyu, Kitila, Tafesse, kelemu, and Zerihun (2019) by optimizing the woman's health and knowledge before planning and conceiving a pregnancy (Kassa and Yohannes, 2018; Demisse et al., 2019, Asresu et al., 2019), this aspect of maternal healthcare has been neglected (Olowokere, Komolafe and Owofadeju, 2015; Kassa and Yohannes, 2018; Asresu et al, 2019). Moos (2006) noted that there are no well-established registered programs for its implementation which is critical to reducing perinatal/maternal morbidity and mortality rates. Few studies done globally showed consistently poor utilization of preconception. Its practice is almost nonexistent in developing countries (Boulet, Parker \& Atrash, 2006; Ezegwui et al., 2009). According to Tokunbo, Abimbola, Polite and Gbemiga (2016), this form of care is still evolving in Nigeria. Currently, a limited number of studies has considered the utilization of preconception care and its associated factors in South-East Nigeria.

This study aimed at assessing the preconception care utilization among women of reproductive age in South-East Nigeria. Objectives of the study are to determine: the proportion of childbearing women that attend preconception reproductive health clinics, the preconception services received by childbearing women in preconception reproductive health clinics, sociodemographic-obstetric determinants of preconception care utilization.

\section{METHODS}

A cross-sectional design was adopted for this study. The research setting was South-East Nigeria with a total number of 4317 documented health facilities (FMO, 2014), a sample size of 35 health facilities was calculated using Measure of Rel. Variance. Simple random sampling was used to select 3 States from the 5 States in South-East Nigeria. Three (3) tertiary health facilities were purposefully sampled from the 3 randomly sampled States. Stratified random sampling was used to select 18 primary and 14 secondary health facilities from the 3 sampled States.

A pre-tested and validated structured Questionnaire on Preconception Care Utilization (QPCU) with a reliability coefficient score of 0.89 was used to collect data from 350 postnatal women who were systematically selected from the 33 facilities at a ratio of 10 clients per facility. Data were collected on their socio-demographic-obstetric characteristics - age, marital status, parity, educational status and occupation, place of residence and pregnancy intention. Sociodemographic-obstetric characteristics of the mothers were categorized and coded as follows: Age 15 - 24 years $=1,25$ - 34 years $=2$ and 35 - 45years, marital status- married $=1$ and single $=2$, educational status- primary $=1$, secondary $=2$ and tertiary $=3$. Preconception care was 
assessed based on attendance to the reproductive health clinic in preparation for conception and services received from the clinic.

Ethical clearance was obtained from Nnamdi Azikiwe University Teaching Hospital, Nnewi Ethics Committee; Health Research Ethics Committee, Federal Medical Centre Umuahia and Health Research Ethics Committee, Federal Medical Centre, Owerri. Verbal consent was extracted from the women after due explanation of the procedure, risk and benefits of the survey. The QPCU was interviewer-administered and this resulted in a $100 \%$ response rate.

Data were collated and entered into SPSS version 20. Data collected on socio-demographicobstetric characteristics of the respondents and utilization of preconception care among the mothers were summarized in frequency distributions and percentages while binary logistic regression was used to determine the association between the socio-demographic-obstetric characteristics of the mothers and utilization of preconception care. Statistical significance was set at $\mathrm{p}<0.05$.

\section{RESULTS}

Table 1: Socio-demographic-obstetric Characteristic of the respondents $\quad \mathbf{n}=\mathbf{3 5 0}$

\begin{tabular}{|c|c|c|c|}
\hline \multicolumn{2}{|l|}{ CHARACTERISTICS } & \multirow{2}{*}{$\begin{array}{l}\text { FREQUENCY } \\
160\end{array}$} & \multirow{2}{*}{$\begin{array}{l}\text { PERCENTAGE } \\
45.7\end{array}$} \\
\hline Age (years) & $15-24$ & & \\
\hline & $25-34$ & 130 & 37.1 \\
\hline & $35-45$ & 60 & 17.2 \\
\hline \multirow[t]{2}{*}{ Marital Status } & Married & 338 & 96.6 \\
\hline & Single & 12 & 3.4 \\
\hline \multirow[t]{2}{*}{ Parity } & Primipara & 110 & 31.4 \\
\hline & Multipara & 240 & 68.6 \\
\hline \multirow[t]{3}{*}{ Mother's education } & Primary & 53 & 30.3 \\
\hline & Secondary & 101 & 57.7 \\
\hline & Tertiary & 20 & 11.4 \\
\hline Mothers Employment & Not employed & 50 & 14.3 \\
\hline \multirow[t]{3}{*}{ Status } & Privately employed & 52 & 14.9 \\
\hline & Self-employed & 200 & 57.1 \\
\hline & Civil servant & 48 & 13.7 \\
\hline \multirow[t]{2}{*}{ Place of residence } & Rural & 178 & 50.9 \\
\hline & Urban & 172 & 49.1 \\
\hline \multirow[t]{2}{*}{ Pregnancy planning } & Planned & 272 & 77.7 \\
\hline & Unplanned & 78 & 22.3 \\
\hline
\end{tabular}

Table 1 shows that a greater proportion of the mothers, $45.7 \% \%$ were aged 15 to 24 years; 96.6\% were married; $68.6 \%$ were multiparous women; $57.7 \%$ had secondary education, $57.1 \%$ were self-employed, $50.9 \%$ were rural dwellers and $77.7 \%$ indicated that their most recent pregnancy was planned while $22 . .3 \%$ indicated unintended pregnancy. 


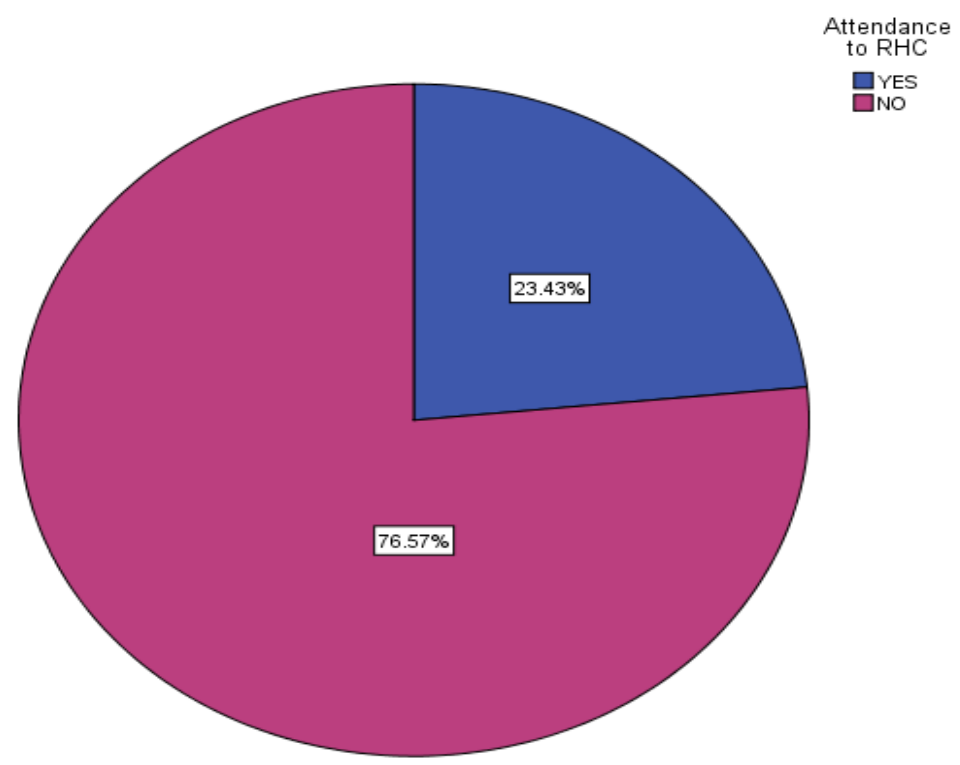

Fig. I: Proportion of Women that Attended Preconception Reproductive Health Clinic

Figure 1 shows that only $23.4 \%$ of the respondents attended preconception clinics before conception of their most recent pregnancy.

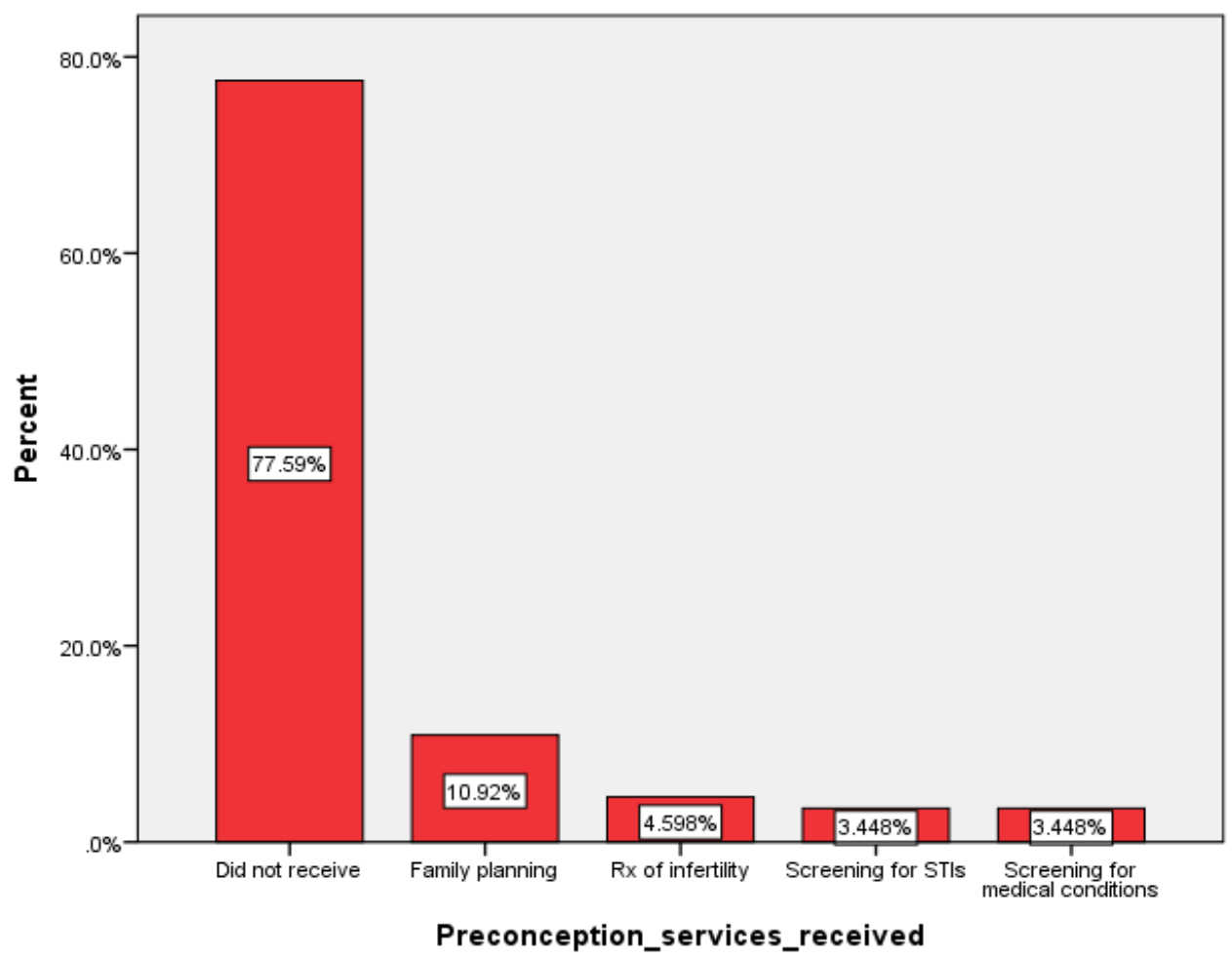

Fig. II: Preconception Services Received

Figure II shows that out of $23.4 \%$ of postnatal mothers who received preconception care, family planning was the commonest preconception service utilized by the mothers $(10.9 \%)$. Over seventy per cent $(77.6 \%)$ did not receive services. 
African Journal of Health, Nursing and Midwifery

ISSN: 2689-9418

Volume 4, Issue 6, 2021 (pp. 1-13)

www.abjournals.org

Table 2: Association between mothers' socio-demographic-obstetric characteristics and preconception care utilization

\begin{tabular}{|c|c|c|c|c|c|}
\hline \multirow[t]{2}{*}{$\begin{array}{l}\text { Demographic } \\
\text { characteristics }\end{array}$} & \multicolumn{2}{|c|}{$\begin{array}{l}\text { Preconception care } \\
\text { utilization }\end{array}$} & \multirow[t]{2}{*}{$\begin{array}{l}\text { P- } \\
\text { value }\end{array}$} & \multirow[t]{2}{*}{$\begin{array}{l}\text { Adjusted Odds Ratio } \\
\text { and } 95 \% \text { CI }\end{array}$} & \multirow[t]{2}{*}{$\begin{array}{l}\text { Likelihood to } \\
\text { utilize PCC }\end{array}$} \\
\hline & Utilized & Not Utilized & & & \\
\hline \multicolumn{6}{|l|}{ Age (Years) } \\
\hline $15-24$ (Ref) & $28(8.0 \%)$ & $68(19.4 \%)$ & 0.420 & 1 & \\
\hline $25-34$ & $42(12.0 \%)$ & $176(50.3 \%)$ & & $0.675(0.284-1.606)$ & \\
\hline $35-45$ & $12(3.4 \%)$ & $24(6.9 \%)$ & & $1.311(0.370-4.649)$ & \\
\hline \multicolumn{6}{|l|}{ Marital Status } \\
\hline Married(Ref) & $80(22.9 \%)$ & $258(73.7 \%)$ & 0.693 & 1 & \\
\hline Single & $2(0.6 \%)$ & $10(2.9 \%)$ & & $0.687(0.068-6.941)$ & \\
\hline \multicolumn{6}{|l|}{ Parity } \\
\hline Primipara(Ref) & $38(10.9 \%)$ & $72(20.6 \%)$ & 0.014 & 1 & \\
\hline Multipara & $44(12.6 \%)$ & $196(56.0 \%)$ & & $0.398(0.190-0.831)^{*}$ & $60.2 \%$ LESS \\
\hline \multicolumn{6}{|c|}{ Mothers' education } \\
\hline Primary (Ref) & \multirow{2}{*}{$\begin{array}{l}34(9.7 \%) \\
42(12.0 \%)\end{array}$} & $72(20.6 \%)$ & 0.146 & 1 & \\
\hline $\begin{array}{l}\text { Secondary } \\
\text { education }\end{array}$ & & $160(45.7 \%)$ & & $2.923(0.745-11.473)$ & \\
\hline $\begin{array}{l}\text { Tertiary } \\
\text { education }\end{array}$ & $6(1.7 \%)$ & $36(10.3 \%)$ & & $1.495(0.397-5.627)$ & \\
\hline \multicolumn{6}{|c|}{ Mothers' occupation } \\
\hline $\begin{array}{l}\text { Not employed } \\
\text { (Ref) }\end{array}$ & $10(2.9 \%)$ & $40(11.4 \%)$ & 0.008 & 1 & \\
\hline $\begin{array}{l}\text { Privately } \\
\text { employed }\end{array}$ & $26(7.4 \%)$ & $26(7.4 \%)$ & & $0.195(0.075-0.508)^{* * k}$ & $80.5 \%$ LESS \\
\hline Self-employed & $36(10.3 \%)$ & $164(46.9 \%)$ & & $0.254(0.072-0.893)^{*}$ & 78.3\% LESS \\
\hline $\begin{array}{l}\text { Government } \\
\text { employed }\end{array}$ & $10(2.9 \%)$ & $38(10.9 \%)$ & & $0.217(0.060-0.788)^{*}$ & $74.6 \%$ LESS \\
\hline
\end{tabular}

Binary logistic regression at 0.05 level of significance; $*=p<0.05, * *=p<0.01$,

Ref $=$ reference group, $\mathrm{PCC}=$ Preconception care 
Table 2: Association between mothers' socio-demographic-obstetric characteristics and preconception care utilization cont.

\begin{tabular}{|l|l|l|l|l|l|}
\hline $\begin{array}{l}\text { Demographic } \\
\text { characteristics }\end{array}$ & $\begin{array}{l}\text { Preconception care } \\
\text { utilization }\end{array}$ & $\begin{array}{l}\text { P- } \\
\text { value }\end{array}$ & $\begin{array}{l}\text { Adjusted Odds Ratio } \\
\text { (AOR) and 95\% CI }\end{array}$ & $\begin{array}{l}\text { Likelihood to } \\
\text { utilize PCC }\end{array}$ \\
\hline & $\begin{array}{l}\text { Not } \\
\text { Utilized }\end{array}$ & & & \\
\hline Place of residence & & & \\
\hline Rural (Ref) & $48(13.7 \%)$ & $130(37.1 \%)$ & & 1 & 3.4 times more \\
\hline Urban & $34(9.7 \%)$ & $138(39.4 \%)$ & 0.205 & $1.595(0.775-3.284)$ & \\
\hline Pregnancy intention & $74(21.1 \%)$ & $198(56.6 \%)$ & 0.033 & $3.396(1.107-10.423)$ & \\
\hline Intended & $70(20 \%)$ & & 1 & \\
\hline $\begin{array}{l}\text { Unintended } \\
\text { Ref) }\end{array}$ & $8(2.3 \%)$ & &
\end{tabular}

Binary logistic regression at 0.05 level of significance; $*=p<0.05, * *=p<0.01$,

Ref $=$ reference group, $\mathrm{PCC}=$ Preconception care

Table 2 shows that parity, mother's occupation and pregnancy intention were significantly associated with their utilization of preconception care. Primiparous mothers were $60.2 \%$ (AOR: 0.398; 95\% CI: $0.190,0.831$ ) less likely to utilize preconception care than multiparous mothers. Mothers working with private establishments were $80.5 \%$ (AOR: $0.195 ; 95 \%$ CI: 0.075, 0.508) less likely to utilize preconception care than mothers who were not working. Similarly, mothers working with government establishments were 78.3\% (AOR: 0.217; 95\% CI: 0.060, 0.788) less likely to utilize preconception care than mothers who were not working. Also, selfemployed mothers were $74.6 \%$ (AOR: 0.254 ; 95\% CI: $0.072,0.893$ ) less likely to utilize preconception care than mothers who were not working. Mothers who indicated that their pregnancies were planned were 3.4 times (AOR: 3.396; 95\% CI: 1.107, 10.423) more likely to utilized preconception care than mothers whose pregnancies were unintended.

\section{DISCUSSION}

Findings of this study showed that a greater proportion of the women was between ages 15 to 24 , the majority were married, and greater proportions of the childbearing women were multiparous and had secondary education, (table 1). In a similar study by Akinajo, Osanyin and Okoji (2019) using a total of 50 women as study participants, the majority of the respondents falls within the age group of 28-30 and 31-33 years, 17 (34\%) and $16(32 \%)$, respectively, with a mean age of $31.5 \pm 3.8$ years. Almost all of the respondents $48(96 \%)$ were married, and 22 $(44 \%)$ were primigravida. Christianity accounted for $45(90 \%)$ of respondents religion and the majority were Yoruba 24 (48\%). Forty (80\%) had tertiary education, whereas $16(32 \%)$ of respondents were civil servants and $8(16 \%)$ were health workers. Bayrami, Didarloo and Asadinejad (2020) also noted in their study carried out among 230 women of childbearing age at Urmia health centres, Northwest Iran in 2019 that the mean age of the participants was 30.73 years (standard deviation $=6.77$ years). Most of the subjects $(87.7 \%)$ were housewives, and $35.6 \%$ of all participants had a high-school diploma. The majority of participants $(47 \%)$ had sufficient income, and $26.9 \%$ had no insurance. Understanding the socio-demographic characteristics of these women is of great importance. These characteristics, for instance, age 
below 16 and above 35 years; primigravida and multiparity; low socio-economic status pose health risks that need to be addressed prior to conception.

The unintended pregnancy rate of $22.3 \%$ found in this study is slightly higher than the $21 \%$ rate reported by Tayo, Akinola, Adewunmi \& Rabiu (2014) in their study, conducted to determine the prevalence of unintended pregnancy among patients attending antenatal clinics in a tertiary hospital in Lagos, South-West Nigeria. It is also higher than $16 \%$ reported by Agida, Akaba, Ekele and Adebayo (2016) in a study carried in University of Abuja Teaching Hospital, Abuja, Nigeria and 14\% noted by Masmalai, Thongthai, Yang and Richter (2010) in Thailand. Much lower rates of $10 \%$ and $8.6 \%$ were noted by Akinajo et al (2019) and Lakha and Glasier (2006) among their participants in a similar study in Lagos University Teaching Hospital, Lagos, Nigeria and Scotland respectively. It is however lower than 26\% reported from Ethiopia, 35.9\% reported by Lamina (2015) in Ogun State, Nigeria. Much higher figures have been reported by Sanga (2014) in a study carried out in Australia (49.4\%), Palena (2009) in Argentina (65\%). The rate of unplanned pregnancy observed in this study is significant and demands the attention of health authorities and mobilization of actions to create awareness of the importance of preconception health care and subsequently improve contraceptive services. Women who conceive without planning for the pregnancies miss the essential health interventions required before pregnancy (Olowokere et al, 2015). Births that are unintended by the mother has been noted to be at elevated risks of adverse social, economic, and health outcomes for the mother and the child (Committee on Health Care for Underserved Women, 2015; Moss \& Snyder, 2015; Agida, 2016). Planning pregnancy can help the mother have a healthy baby. Babies who are planned are more likely to be born healthy than babies who are not planned (Centers for Disease Control and Prevention, 2020).

The overall utilization of preconception health care among childbearing women in South-East Nigeria was low. Only $23.4 \%$ of the mothers utilized at least one of the components of preconception care (figures I \& II). It was however higher than studies conducted in Sudan, 9\% (Khalid et al, 2016); Ethiopia, 13..4\% (Demisse et al.,); Brazil, 15.9\% (Borges et al., 2016); Ethiopia, 16.27\% (Ayele, Belay, Kassa and Worke, 2021); Urmia, Northwest Iran, 19.6\% (Bayrami, Didarloo and Asadinejad, 2020); China, 26.6\% (You, Tan, Hu, Wu, Jiang, Peng, ... Qian, 2015) and Abakaliki, 10.3\% (Elkem et al, 2018); but lower than studies conducted in Kenya, 25.8\% (Okemo et al., 2020); London, 27\% (Stephenson et al, 2014); Sri Lanka, 27.2\% (Patabendige and Goonewardene, 2012); Saudi Arabia, 29.3\% (Madanat and Sheshah, 2016); Maryland, 32\% (Maryland Pregnancy Risk Assessment Monitoring System) and LUTH, $34.2 \%$ (Akinajo et al, 2019). The possible explanation for these variations might be due to differences in the study settings, study participants and health care systems of the countries. The general poor utilization of preconception care by women is a source of concern considering the numerous benefits of preconception care and its central role in the reduction of perinatal morbidity and mortality.

Regarding the predictors of preconception care utilization, the researchers noted a significant association between parity and utilization of preconception care $(p=0.01)$. The odds ratio $(O R)$ of utilizing preconception care were $60.2 \%$ lower among multiparous women than primiparous women. This finding is contrary to findings of Goshu, Liyeh and Ayele (2018) who noted that multiparous women were 2.3 times more likely to utilize preconception care than women who were primiparous in North-West Ethiopia. It is also not supported by findings of the studies done in Iran by Shadab, Nekuei and Yadegarfar (2017). On the other hand, Ezegwui, Dim and Ikeme, (2009) noted no significant association between parity and utilization of preconception 
care among antenatal women in the University of Nigeria Teaching Hospital and Enugu State University Teaching Hospital, Enugu State, Nigeria.

Occupation of a woman was found to be significantly associated with the utilization of preconception care. Mothers working with private establishments were $80.5 \%$ less likely to utilize preconception care than mothers who were not working. Similarly, mothers working with government establishments were $78.3 \%$ less likely to utilize preconception care than mothers who were not working. Also, self-employed mothers were $74.6 \%$ less likely to utilize preconception care than mothers who were not working. This finding concurred with the finding of Chepngetich (2018) who noted that there was a significant association between the occupation of a woman and the utilization of the preconception care services among women of reproductive age in Kiambu county, Kenya. This association may be due to lack of chance and inability to obtain permission from work. This can hamper the ability of a working-class woman to attend preconception clinic especially if there is no obvious health challenge that is warranting them to attend preconception health care.

Mothers whose pregnancy was intended were 3.4 times more likely to utilize preconception care than mothers whose pregnancy was unintended (AOR: 3.396; CI: 1.107, 10.423). This finding corresponds with the findings of Goshu, Liyeh, and Ayele (2018) who reported childbearing women in Adet, North-West, Ethiopia whose pregnancies were intended were 3.3 times more likely to utilize preconception care than women whose pregnancy was unintended. Similar findings were reported in studies done in Maryland, Brazil and Iran by Connor, Cheng and Strobino (2014), Borges et al (2016) and Shadab, Nekuei and Yadegarfar (2017) respectively. A possible explanation for this finding is that women who planned to be pregnant may likely seek medical advice and/or other health care before becoming pregnant.

\section{CONCLUSION}

Findings of this study showed that preconception care utilization was very poor in South-East Nigeria. From this study, being multiparous mothers, women who are employed in private establishments, women who did not plan their pregnancy were more likely not to utilize preconception care. There is a serious need to create awareness of preconception care among childbearing women. They should be armed with detailed and accurate information on preconception care. Health facilities should establish functional clinics with the availability of evidence-based guidelines to improve uptake of preconception care. Health care professionals especially doctors, nurses and midwives are the key players in promoting maternal and child health, and as such, they should intensify their efforts in encouraging women to receive this care and to constantly emphasize the importance and benefits of PCC during routine hospital visits. Employers of childbearing women should grant them the opportunity to attend preconception clinics as at when due. 


\section{REFERENCES}

Agida, T. E., Akaba, G. O., Ekele, B. A. \& Adebayo, F. (2016). Unintended pregnancy among antenatal women in a tertiary hospital in North Central Nigeria. Nigeria Medical Journal, 57(6), 334-8. DOI: 10.4103/0300-1652.193859

Ahmed, K. Y. M., Elbashir, I. M. H., Mohamed, S. M. I., Saeed, A. K. M. \& Alawad, A. A. M. (2015). Knowledge, attitude and practice of preconception care among Sudanese women in reproductive age about rheumatic heart disease at Alshaab and Ahmad Gassim hospitals 2014-2015 in Sudan. Basic Res J Med ClinSci, 4, 199-203.

Akinajo, O. R., Osanyin, G. E. \& Okojie, O. E. (2019). Preconception care: Assessing the level of awareness, knowledge and practice amongst pregnant women in a tertiary facility. Journal of Clinical Sciences. 16(3):87-92. DOI: 10.4103/jcls.jcls_41_18

Asresu, T. T., Hailu, D., Girmay, B., Abrha, M. W. \& Weldearegay, H. G. (2019). Mothers' utilization and associated factors in preconception care in northern Ethiopia: a community-based cross-sectional study. BioMed Central Pregnancy and Childbirth, 19, 347. DOI: https://doi.org/10.1186/s12884-019-2478-1

Ayele, A. D., Belay, H. G., Kassa, B. G. \& Worke, M. D. (2021). Knowledge and utilisation of preconception care and associated factors among women in Ethiopia: systematic review and meta-analysis. Reproductive Health 18, 78. https://doi.org/10.1186/s12978-021-01132-9

Bayrami, R., Didarloo, A. \& Asadinejad, A. (2020). Predictors of preconception care behaviour among women of reproductive age using a behaviour-change model. SingHealth, 30(2). https://doi.org/10.1177/2010105820958727

Borges, A. L.V., Santos, O. A., Nascimento, N. C., Chofakian, C. B. N. \& Sponholz, F. A. (2016). Preconception health behaviours associated with pregnancy planning status among Brazilian women. Rev Esc Enferm USP 50, 208-215.DOI: http://dx.doi.org/10.1590/S0080-623420160000200005.

Boulet, S. L., Parker, C. \& Atrash, H. (2006). Preconception care in international settings. Maternal Child Health Journal,10, 29-35.

Centres for Disease Control and Prevention (2020). Planning for pregnancy, preconception care. https://www.cdc.gov/preconception/planning.html. Accessed January 2021

Chepngetich, J. (2018). Utilization of preconception care services among women of reproductive age in Kiambu County, Kenya. A research thesis submitted in partial fulfilment of the requirements for the award of the degree of master of public health (reproductive health) in the school of public health of Kenyatta University. P139/CE/26571/2011. July 2018.

Chola L., Pillay, Y., Barron, P., Tugendhaft, A., Kerber, K. \& Hofman, K. (2015). Cost and impact of scaling up interventions to save lives of mothers and children: taking South Africa closer to MDGs 4 and 5. Glob Health Action, 8:27265 15. DOI: 10.3402 /gha.v8.27265

Committee on Health Care for Underserved Women. (2015). Committee opinion no 615: Access to contraception. Obstetrics and Gynecology, 125, 250-5.

Connor, K. A., Cheng, D. \& Strobino, D. (2014). Preconception health care among Maryland women. Maternal and Child Health Journal, 18, 2437.

Dean S, et al (2013). Setting research priorities for preconception care in Low- and MiddleIncome Countries: aiming to reduce maternal and child mortality and morbidity. PLoS Med., 10(9):e1001508. 
Demisse, T. L., Aliyu, S. A., Kitila, S. B.,Tafesse, T. T., Kelemu, A. G. \& Zerihun, M. S. (2019). Utilization of preconception care and associated factors among reproductive age group women in DebreBirhan town, North Shewa, Ethiopia. Reproductive Health. 16, 96. doi.org/10.1186/s12978019-019-0758-x

Ekem, N. N., Lawani, L. O., Onoh, R. C., Iyoke, C. A., Ajah, L.O., Onwe, E.O., ... Okafor, L. C.(2018). Utilization of preconception care services and determinants of poor uptake among a cohort of women in Abakaliki South-East Nigeria. Journal of Obstetrics and Gynaecology. 38(6):738-744. Doi.org/10.1080/01443615.2017.1405922

Ezegwui, H. U., Dim, N. \& Ikeme, A. C. (2009). Preconception care in South-Eastern Nigeria. Journal of Obstetrics and Gynaecology, 28(8),765-768. Doi.org/10.1080/01443610802462647

Goshu, Y. A., Liyeh, T. M. \&Ayele, A. S. (2018). Preconception care utilization and its associated factors among pregnant women in Adet, North-Western Ethiopia (Implication of Reproductive Health). Journal of Women's Health Care, 7, 445. doi:10.4172/2167-0420.1000445

Kassa, A. \&Yohannes, Z. (2018). Women's knowledge and associated factors on preconception care at public health institution in Hawassa City, South Ethiopia. BioMed Central, 11, 841. https://doi.org/10.1186/s13104-018-3951-z.

Johnson et al (2006). Recommendations to improve preconception health and health careUnited States. A report of the CDC/ATSDR Preconception Care Work Group and the Select Panel on Preconception Care. Atlanta: 2006/55(RR06):1-23. https://www.cdc.gov/mmwr/preview/mmwrhtml/rr5506a1.htm

Ahmed, K. Y. M., Elbashir, I. M. H., Mohamed, S. M. I., Saeed, A. K. M. \& Alawad, A. A. M. (2015). Knowledge, attitude and practice of preconception care among Sudanese women in reproductive age about rheumatic heart disease. International Journal of Public Health Research, 3(5), 223-227.

Lakha, F. \& Glasier, A. (2006). Unintended pregnancy and use of emergency contraception among a large cohort of women attending for antenatal care or abortion in Scotland. Lancet, 18; 368(9549): 1782-7. doi: 10.1016/S0140-6736(06)69737-7.

Lamina, M. A. (2015). Prevalence and determinants of unintended pregnancy among women in Southwestern Nigeria. Ghana Medical Journal, 49, 187-94.

DOI: 10.4314/gmj.v49i3.10. Accessed December 30, 2020.

Masmalai, A., Thongthai, V., Yang X. \& Richter (2010). The effect of unwanted pregnancy on prenatal care practice in Thailand. Journal of population and social studies, 19(1),

123 - 137. https://so03.tci-thaijo.org

Madanat, A. Y. \& Sheshah, E. A. (2016). Preconception care in Saudi women with diabetes mellitus. Journal of Family Community Medicine, 23(2),109. doi: 10.4103/2230$\underline{8229.181012}$

Maryland Pregnancy Risk Assessment Monitoring System. (2013). Preconception care among Maryland women giving birth 2009-2011.The 2009 - 2011 Maryland

Pregnancy Risk Assessment Monitoring SystemSurvey.

health.maryland.gov/phpa/mch/Documents/prams_preconception_care.pdf

Mazza, D. \& Chapman, A. (2010). Improving the uptake of preconception care and periconceptional folate supplementation: what do women think? BioMed Central Public Health, 10, 786. https://doi.org/10.1186/1471-2458-10-786. 
Moos, M. K. (2006). Preconception health: Where to from here? Women's Health, 16, 156-8. Moss, D. A., Snyder, M. J. \& Lu, L. (2015). Options for women with unintended pregnancy. American Family Physician, 91(8), 544-9. Accessed December 30, 2020, from https://pubmed.ncbi.nlm.nih.gov/25884862/

New York State Department of Health AIDS Institute (2010. Preconception Care for HIVInfected Women. Accessed December 30, 2020, from https://www.thebodypro.com/article/preconception-care-hiv-infected-women

Okemo, J., Temmerman, M., Mwaniki \& Kamya, D. (2020). Preconception Care among Pregnant Women in an Urban and a Rural Health Facility in Kenya: A Quantitative Study. International Journal of Environmental Research and Public Health, 17, 74304 of 11. https://www.researchgate.net > publication > 323701497

Oklahoma Pregnancy Risk Assessment Monitoring System. (2010). Preconception care among Oklahoma women, pregnancy risk assessment monitoring system. Maternal Child Health Service, 14(1). Accessed January 20, 2021, from https://www.ok.gov health2 Pra...

Olowokere, A. E., Komolafe, A. \& Owofadeju, C. (2015). Awareness, knowledge and uptake of preconception care among women in Ife central-local government area of Osun State, Nigeria. Journal of Community Medicine Primary Health Care, 27:83-92.

Palena, C., Bahamondes, M. V., Schenk, V., Bahamondes, L. and Fernandez-Funes, J. (2009). High rate of unintended pregnancy among pregnant women in maternity hospitals in Cordoba, Argentina: A pilot study. Reproductive Health, 6,11.

Patabendige, M. \& Goonewardene, R. (2012). Preconception care received by women attending antenatal clinics at a Teaching Hospital in Sri Lanka. Journal of Obstetrics and Gynaecology, 33.

Khan, R. A. (2018). Preconception health \& counselling-are we doing enough?

Developments Clinical Medical Pathology, 1,3. Accessed January 20, 2021, from https?crimsonpublishers.com/dcmp/pdf/DCMP.00512.pdf

Sanga, K., Mola, G., Wattimena, J., Justesen, A. \& Black, K. I. (2014). Unintended pregnancy amongst women attending antenatal clinics at the Port Moresby General

Hospital. Australia. New Zealand Journal of Obstetrics and Gynaecology, 54, 360-

5. Doi:https://doi.org/10.1111/ajo.12219

Shadab, P., Nekuei, N. \&Yadegarfar, G. (2017). The prevalence of preconception care, its relation with recipients' individuality, fertility, and the causes of lack of checkup in women who gave birth in Isfahan hospitals in 2016. Journal of Education Health Promotion, 6, 88 .

Sriprasert I, Chaovisitsaree S, Sribanditmongkhol N, Sunthornlimsiri N, Kietpeerakool C. Unintended pregnancy \& associated risk factors among young pregnant women. Int J GynaecolObstet 2015;128:228-31. DOI: 10.1016/j.ijgo.2014.09.004

Steel, A., Lucke, J. \& Adams, J. (2015). The prevalence and nature of the use of preconception services by women with chronic health conditions: an integrative review. BioMed Central Women's Health, 15,14. doi: 10.1186/s12905-015-0165-6

Stephenson, J., Patel, D., Barrett, G., Howden, B., Copas, A., Ojukwu, O., P. \& Shawe, J.

(2014). How do women prepare for pregnancy? Preconception experiences of women attending antenatal services and views of health professionals. PLos, 9(7):e103-085.

https://doi.org/10.1371/journal.pone.0103085 
Taiwo, A. L. \& Amos, O. A. (2014). Determinants of folic acid intake during preconception and in early pregnancy by mothers in Ibadan. The Pan African Medical Journal, 19,113 .

Tayo, A. O., Akinola, O. I., Adewunmi, A. A. \& Rabiu, K. A. (2014). Prevalence of unintended pregnancy among patients attending antenatal clinics in a tertiary hospital in Lagos, South-West Nigeria. International Journal of Medical Science, 14(4), 4750 .

Tokunbo, O. A., Abimbola, O. K., Polite, I. O. \& Gbemiga, O. A. (2016). Awareness and perception of preconception care among health workers in Ahmadu Bello University Teaching Hospital, Zaria. Tropical Journal of Obstetrics and Gynaecology, 149-52

You, X., Tan, H., Hu, S., Wu, J., Jiang, H., Peng, A., Yue, D., Y., Wang, L., Guo, S. \& Qian, X. (2015). Effect of preconception counselling on maternal health care of migrant women in China: a community-based, cross-sectional survey. Biomedicine Central Pregnancy and Childbirth, 15, 55. https://doi.org/10.1186/s12884-015-0485-4

Williams, L., Zapata, L. B., D'Angelo, D. V., Harrison, L. \& Morrow, B. (2012). Associations between preconception counselling and maternal behaviours before and during pregnancy Maternal Child Health Journal, 16(9), 1854-61. doi: 10.1007/s10995-011-0932-4.

World Health Organization (2013a). Preconception care: Maximizing the gains for maternal and child health. Policy Brief. Accessed December 30, 2020, fromhttps://www.who.int/maternal_child_adolescent/documents/preconception_care_p olic y_brief.pdf

World Health Organization (2013b). Meeting to develop a global consensus on preconception care to reduce maternal and childhood mortality and morbidity. Geneva: World Health Organization.

World Health Organization (2016). WHO Fact sheet $N^{\circ} 348$. Updated November 2016.

Zhao, X., Jiang, X., Zhu, J., Li, G., He, X., Fengying, M., Meng, Q., Cao, Q., Meng, Y., Howson, C., Zhong, N. \&Tian, Y. (2014). Factors influencing the quality of preconception healthcare in China: applying a preconceptional instrument to assess healthcare needs. BioMed Central Pregnancy Childbirth, 14, 360. http://doi.org/10.1186/1471- 2393-14-360

\author{
Abbreviations \\ AOR $=$ Adjusted Odd Ratio \\ $\mathrm{PCC}=$ Preconception care \\ $\mathrm{CI}=$ Confident interval
}

\title{
Acknowledgement
}

The researchers appreciate our respondents for their patience and contribution to this study. We are very grateful to the Research and Health Ethics Committees of Nnamdi Azikiwe University Teaching Hospital, Nnewi; Federal Medical Centre, Owerri and Umuahia for the approval of the ethical clearance and their technical input. 